\title{
ASPECTOS MORFOLÓGICOS E INFLUÊNCIA DO TAMANHO DA SEMENTE NA GERMINAÇÃO DO JAMBO-VERMELHO ${ }^{1}$
}

\author{
RAQUEL SILVA COSTA², INEZ VILAR DE MORAIS OLIVEIRA³, FABÍOLA VITTI MÔRO4, \\ ANTÔNIO BALDO GERALDO MARTINS ${ }^{5}$
}

\begin{abstract}
RESUMO - O jambo-vermelho (Syzygium malaccense (L.) Merryl et Perry), espécie pertencente à família Myrtaceae, possui frutos ricos em vitaminas, ferro e fósforo. Este trabalho teve por objetivos fornecer informações sobre aspectos morfológicos do fruto, semente e plântula e avaliar a influência do tamanho da semente na germinação dessa espécie. O fruto é uma baga piriforme, carnoso e indeiscente. O epicarpo é delgado, liso e avermelhado; o mesocarpo e o endocarpo são esbranquiçados e suculentos. Os frutos pesam, em média, 35,57g e medem 7,16cm de comprimento e 5,15cm de largura. As sementes são poliembriônicas e exalbuminosas, pesando, em média, 7,62g. Os cotilédones são maciços e esverdeados. A germinação é hipógea, e a emergência das plântulas inicia-se aos 36 dias após a semeadura. A raiz primária é longa e esbranquiçada. As raízes secundárias são curtas e filiformes. As sementes de maior tamanho são as mais vigorosas, não havendo diferença entre as de tamanho médio e pequeno. O estudo morfológico do jambo-vermelho pode ser utilizado para a identificação da espécie ou em relações ecológicas interespecíficas. Termos para indexação: Sysygium malaccense, vigor, geminação, tamanho de sementes.
\end{abstract}

\section{MORPHOLOGICAL ASPECTS AND INFLUENCE OF THE SEED SIZE IN THE GERMINATION OF WAX JAMBU}

\begin{abstract}
The fruits of wax jambu (Syzygium malaccense (L.) Merryl et Perry), species belonging to the Myrtaceae family, is a source of vitamins, iron and phosphorus. This work aimed to supply information on morphological aspects of the fruit, seed and seedling and to evaluate the influence of the seed size in the germination of this species. The fruit is a pear-shaped bacca, juicy and undeiscent. The epicarp is thin, smooth and redish; the mesocarp and the endocarp are whitish and succulent. The fruits weigh, in average, 35,57g and measure 7,16cm in length and 5,15cm in width. The seeds are polyembrionic and unalbuminous, weighing, in average, 7,62g. The cotyledons are massive and greenish. The germination is hypogeal and the emergency of the seedlings starts at 36 days after the sowing. The primary root is long and whitish. The secondary roots are short and filiform. The large seeds are most vigorous and it doesn't have difference between the seeds of medium and small size. The morphological study of the wax jambu may be used to the identification of the species or in interespecifics ecologics relations.
\end{abstract}

Index terms: Sysygium malaccense, vigor, germination, seed size.

Syzygium malaccense, árvore da família Myrtaceae, popularmente conhecida como jambo-vermelho, tem origem asiática, mais especificamente da Índia e da Malásia. No Brasil, é encontrado nos estados da região Norte, Nordeste e nas regiões quentes do Sudeste A planta pode atingir de 12 a $15 \mathrm{~m}$ de altura, com tronco reto e copa densa, com forma piramidal e ramificação abundante que se inicia a 1,5$2 \mathrm{~m}$ do solo (Cavalcante, 1996). De agosto a fevereiro, época da florada, ela se recobre de flores vermelhas, dando-lhe um aspecto bastante ornamental. Os frutos desenvolvem-se desta data até a época de colheita, que se dá de janeiro a maio. Sua propagação comumente é realizada por sementes (Donadio et al., 1998).

$\mathrm{O}$ fruto pode ser consumido in natura ou em forma de compotas. Segundo Kurosawa (2004), contém vitaminas A, B1, B12, além de cálcio, ferro e fósforo. De acordo com Donadio et al.(1998), a polpa, que constitui $84 \%$ do fruto, apresenta Brix de 6,8\% e acidez de $0,4 \%$, no final da maturação. A bebida obtida da decocção da casca do tronco pode ser utilizada como paliativo para dores de estômago e diarréia (Ahmad \& Ismail, 2003).

Os conhecimentos da morfologia da unidade de dispersão, da germinação, do crescimento e do estabelecimento da plântula são imprescindíveis para compreender o ciclo biológico e a regeneração natural da espécie (Oliveira, 1993), assim como, pode ser útil em estudos de manejo e conservação da fauna silvestre (Kuniyoshi, 1983).

De acordo com Gunn (1981), tanto as características externas quanto as internas das sementes são pouco modificadas pelo ambiente, constituindo-se um fator bastante favorável para a identificação de espécies. Uma vez que as diferentes espécies apresentam variação de tamanho, forma, coloração e aspectos superficiais de suas sementes, essas características permitem separar espécies do banco de sementes do solo, contribuindo para um melhor entendimento da sucessão e regeneração em ecossistemas florestais (Beltrati, 1992).

O estudo morfológico das sementes e plântulas, além de fornecer informações sobre a germinação, armazenamento, viabilidade e métodos de semeadura, auxilia em trabalhos de análise do ciclo vegetativo das espécies, fornecendo subsídios na sua identificação. Com base nas ilustrações obtidas, pode-se facilitar e padronizar a identificação (Silva et al., 1995).

A descrição e a classificação de frutos constituem um capítulo complexo no campo da morfologia vegetal, pois tanto as descrições como as conceituações são, em geral, restritas e imperfeitas (Vidal, 1978).

A descrição morfológica de plântulas contribui na interpretação e padronização de metodologias e testes de germinação que se baseiam em avaliações de plântulas normais e anormais (Oliveira, 1993)

Até recentemente, não se tinha dado a devida importância ao estudo da morfologia de sementes e plântulas de espécies tropicais, devido à falta de tradição no uso dessas características e de informações sobre a biologia reprodutiva de alguns taxa. Entretanto, esses estudos têm recebido progressiva atenção dos pesquisadores (Miquel, 1987; Oliveira \& Beltrati, 1992; Garwood, 1995).

Assim, o presente trabalho teve como objetivo estudar as características morfológicas do fruto, da semente, do processo germinativo e a influência do tamanho de sementes de jambo-vermelho sobre sua germinação.

O trabalho foi realizado na Faculdade de Ciências Agrárias e Veterinárias (FCAV), Universidade Estadual Paulista Júlio de Mesquita

\footnotetext{
${ }^{1}$ (Trabalho 104/2005). Recebido: 23/06/2005. Aceito para publicação: 23/02/2006.

2 Bióloga, Msc, Aluna de Pós-Graduação em Agronomia - Genética e Melhoramento de Plantas - UNESP - FCAV - Depto de Biologia Aplicada. Tel: (16)32092620. e-mail: rscosta@fcav.unesp.br. Bolsista CNPq.

${ }^{3}$ Eng. Agr., Msc, Aluna de Pós-graduação em Agronomia - Produção Vegetal - UNESP - FCAV - Depto de Produção Vegetal. Via de acesso Prof. Paulo Donato Castellane, s/n. Cep: 14884-900. Jaboticabal/SP. Tel/Fax: (16)32092668. e-mail: inezvilar@yahoo.com. Bolsista CAPES.

${ }^{4}$ Eng. Agr., Prof ${ }^{a}$ Dra $^{\mathrm{a}}$ - UNESP - FCAV - Depto. de Biologia Aplicada à Agropecuária e-mail: fabiola@fcav.unesp.br

${ }^{5}$ Eng. Agr., Prof. Dr. - UNESP - FCAV - Depto de Produção Vegetal. e-mail: baldo@fcav.unesp.br
} 
Filho, câmpus de Jaboticabal-SP. A caracterização morfológica do fruto, da semente e da plântula foi realizada no laboratório de Morfologia Vegetal, Departamento de Biologia Aplicada à Agropecuária, e a avaliação da influência do tamanho das sementes sobre a germinação, na Área Experimental de Produção de Mudas Frutíferas do Departamento de Produção Vegetal, sob condições de ripado (50\% de luminosidade).

Os frutos foram coletados de três plantas pertencentes ao Banco de Germoplasma do Departamento de Produção Vegetal da FCAV. Foram utilizados 50 frutos, dos quais foram descritos os seguintes aspectos: coloração, textura, consistência e teor de água no pericarpo, deiscência, peso, partes constituintes e dimensões (comprimento e largura).

As sementes foram separadas em pequenas, médias e grandes (20 sementes para cada tamanho), sendo obtido o número médio de embriões/semente. Para a caracterização das sementes, foram consideradas as seguintes características: coloração, textura e consistência do tegumento; peso; dimensões; presença ou não de tecido de reserva e, tipo, coloração, forma e posição do embrião.

Para a observação e documentação do processo germinativo e morfologia das plântulas, 25 sementes foram semeadas em bandeja contendo vermiculita, textura média, como substrato, em temperatura ambiente. Foram feitas observações diárias para a detecção do momento de protusão da raiz primária, sendo então coletadas amostras para documentação dessa fase. A intervalos representativos dos diversos estádios da germinação, foram coletadas amostras das plântulas, em fases seqüenciais de desenvolvimento, evidenciando: desenvolvimento da raiz primária; surgimento de raízes secundárias e expansão dos cotilédones; início do crescimento da primeira folha e gema apical conspícua; expansão da folha primária e início do desenvolvimento da segunda folha; planta jovem, com nomófilos e os cotilédones em início de fenecimento.

As dimensões e o peso dos frutos e sementes foram obtidos com auxílio de paquímetro digital e balança de precisão, respectivamente. A documentação dos frutos e sementes foi feita em câmera fotográfica digital, e as ilustrações de embriões e plântulas em desenvolvimento foram efetuadas a olho nu ou em estereomicroscópio com câmara-clara acoplada. Os termos empregados e métodos utilizados foram baseados em Barroso (1999) e Damião Filho (1993). A descrição das plântulas foi feita segundo Oliveira (1993).

As sementes foram extraídas manualmente de frutos maduros. Após a extração, as sementes foram lavadas em água corrente, secas à sombra por 24 horas e colocadas para germinar em caixas plásticas, contendo substrato vermiculita, de textura média.

O delineamento experimental foi inteiramente casualizado, com três tratamentos, caracterizados pelo tamanho das sementes (pequeno, médio e grande), separadas de acordo com a medida do seu diâmetro (Tabela 1). Cada parcela foi composta por 10 sementes, com números diferentes de repetições por tratamento, sendo: tamanho pequeno com 7 repetições, médio com 13 repetições e grande com 5 repetições.

A avaliação do número de plântulas emergidas foi feita semanalmente, a partir do início da emergência até sua estabilização. Por se tratar de uma semente poliembriônica, foram contadas todas as plântulas produzidas em cada repetição de 10 sementes, sendo então calculadas as médias de cada tratamento. $\mathrm{O}$ índice de velocidade de emergência (IVE) foi calculado pela fórmula de Maguire (1962).

TABELA 1 - Índice de velocidade de emergência (IVE) e número médio de plântulas de jambo-vermelho, em função do tamanho da semente.

\begin{tabular}{ccc}
\hline TAMANHO DA & IVE & $\begin{array}{c}\text { NÚMERO MÉDIO DE } \\
\text { PLÂNTULAS }\end{array}$ \\
\hline SEMENTE $(\mathbf{m m})$ & $0,237 \mathrm{~b}$ & $13,14 \mathrm{~b}$ \\
$17,34 \pm 5,1$ (Pequeno) & $0,360 \mathrm{ab}$ & $20,61 \mathrm{a}$ \\
$24,00 \pm 2,33$ (Médio) & $0,459 \mathrm{a}$ & $26,00 \mathrm{a}$ \\
$31,66 \pm 2,12$ (Grande) & a
\end{tabular}

*Médias seguidas de mesma letra na coluna não diferem entre si, pelo teste de Tukey, a 5\% de probabilidade.
Os frutos de jambo-vermelho são piriformes, carnosos, indeiscentes, do tipo bacóide. O epicarpo é delgado, liso e de coloração variando de acordo com o estádio de maturação (rosa, vermelho, vermelho-escuro a vermelho bem escuro); o mesocarpo e o endocarpo são esbranquiçados e suculentos, constituindo a polpa (Figura 1 A-D). Possuem, em média, 35,57g (variando de 23,50 a 45,50g); peso da polpa de 27,95g (variando de 18,00 a 32,50g); comprimento de 7,16 cm (variando de 6,37 a 7,85cm) e largura de 5,15cm (variando de 3,96 a 6,22cm).

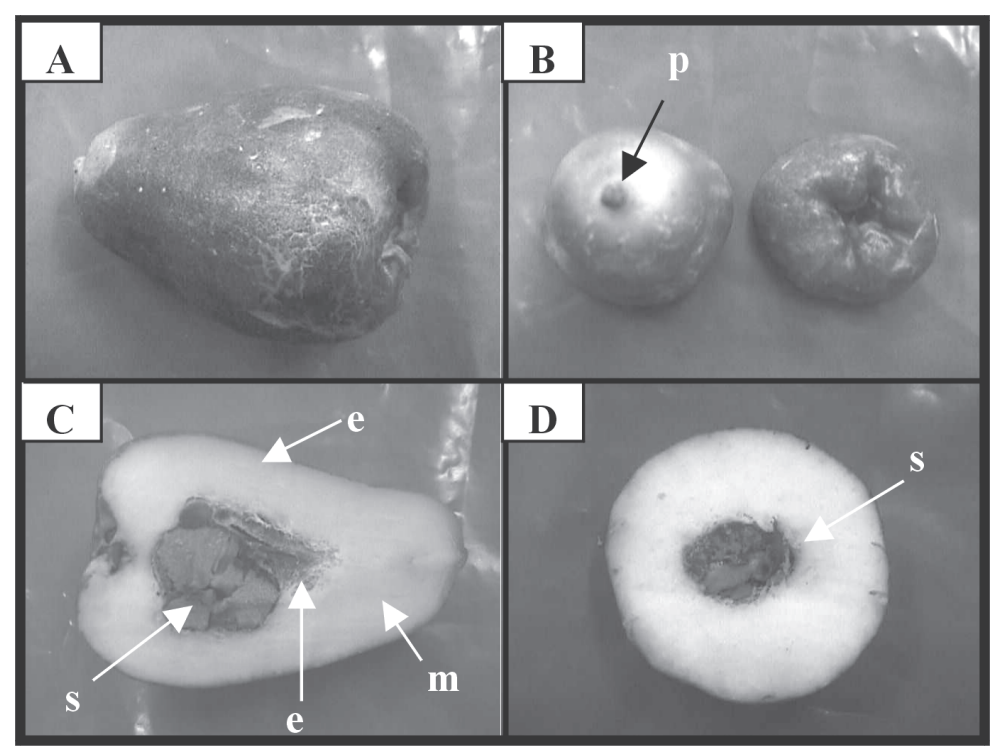

FIGURA 1 - Fruto de jambo-vermelho. A) fruto inteiro; B) pedúnculo (p); C) fruto em corte longitudinal: epicarpo (e), mesocarpo (m), endocarpo (en) e semente poliembriônica (sp); D) fruto em corte transversal : semente (s).

As sementes são poliembriônicas, eurispérmicas, bitegumentadas, de coloração castanho-escura e exalbuminosas (Figura 2 A e B). Possuem peso médio de 7,62g (variando de 2,00 a 20,5g). Os embriões são invaginados, globosos-plicados, apresentando dois cotilédones grandes, esverdeados, de consistência carnosa. O eixoembrionário é esbranquiçado com plúmula arroxeada (Figuras 2B e 3). De acordo com Oliveira (1993), os cotilédones apresentam forma e número definidos nas espécies, constituindo-se caracteres hereditários estáveis muito úteis nos estudos taxonômicos intraespecíficos. O

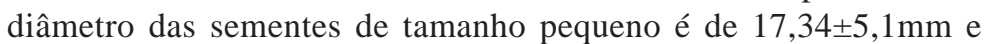
apresentam, em média, 4,2 embriões por semente (variando de 2 a 7

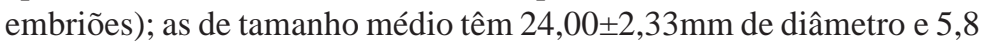
embriões/semente (variando de 4 a 11 embriões); as de tamanho grande

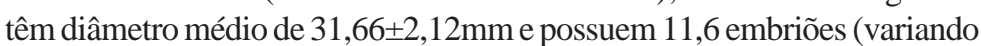
de 7 a 18 embriões).

A germinação de jambo-vermelho é hipógea, e a emergência das plântulas inicia-se, em média, 36 dias após a semeadura. Em cada semente, podem desenvolver-se duas ou mais plântulas. A fase inicial do desenvolvimento pós-seminal é marcada pela emissão de uma raiz primária de coloração branca. A seguir, evidencia-se a raiz primária, que é longa, axial e esbranquiçada (Figuras 2A e 4A) e que, posteriormente, adquire coloração amarelo-parda, tendo início a formação de raízes

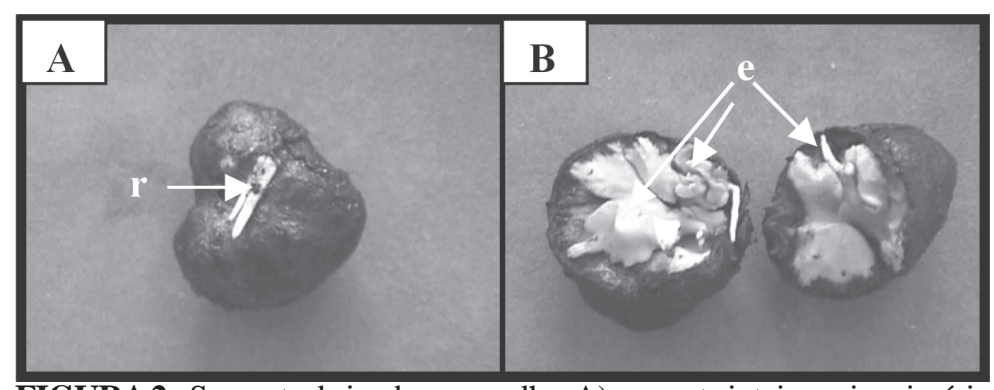

FIGURA2 - Semente de jambo-vermelho.A) semente inteira: raiz primária (rp); B) semente aberta com embriões (e). 
secundárias curtas e filiformes (Figura 4 B). O colo é levemente engrossado, e o hipocótilo é muito reduzido e de coloração verde (Figura 4 B). Os cotilédones são classificados, quanto à sua forma e função, na categoria de cotilédones de reserva; são maciços, apresentando parcial fusão, divididos em porções crassas e esverdeadas (Figuras 2B e 4BD). O epicótilo é longo, ereto, cilíndrico, robusto e de coloração verde (Figura 4B-D). As características do hipocótilo, tais como tamanho, cor, conformação geral, etc., são úteis na delimitação de gênero e na identificação em nível de espécie (Oliveira, 1993).

A plúmula é esverdeada e conspícua (Figura 4B), dando início ao crescimento das folhas primárias. Em seguida, as folhas primárias se expandem, originando nomófilos simples, peciolados, com limbo de forma

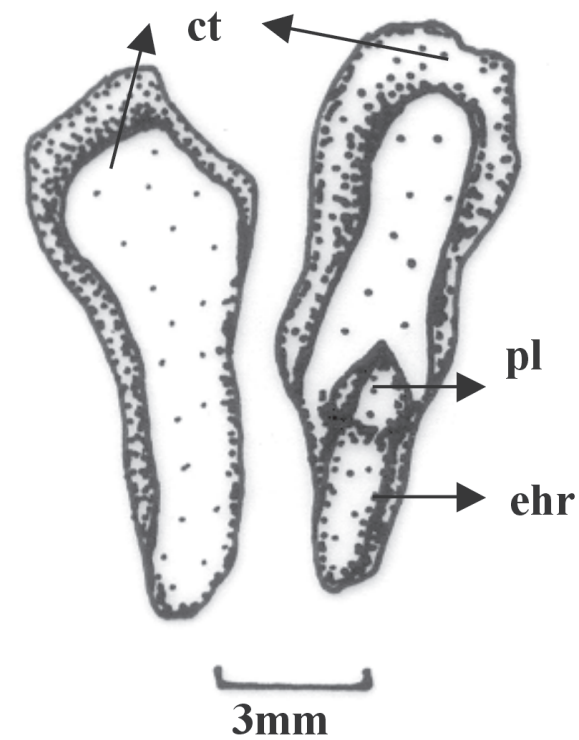

FIGURA 3 - Esquema do embrião de Sysygium malaccense onde se pode observar o eixo hipocótilo-radícula (ehr), a plúmula (pl) e os cotilédones (ct). elíptica, margem lisa e venação reticulada penada (Figura 4C-E). Concomitantemente à expansão da folha primária, há o início do desenvolvimento do segundo par de folhas (Figura 4D). Na planta jovem, observa-se nomófilos mais desenvolvidos e cotilédones em início de fenecimento (Figura 4E). As observações das formas foliares, nas diferentes fases juvenis até a ocorrência dos metáfilos, são de muita valia no conhecimento de cada espécie e na sua identificação (Oliveira, 1993).

As sementes de tamanhos grande e médio foram as que apresentaram maiores valores de IVE e, devido ao fato de essas sementes possuírem maior número de embriões, originaram também maior número de plântulas. Para as sementes de tamanho pequeno, observaram-se valores inferiores (Tabela 1 ).

Resultados semelhantes foram obtidos por Oliveira et al. (2003) em estudo sobre a influência do tamanho da semente na precocidade de germinação de bacuripari (Rheedia gardneriana), que verificaram maiores valores de IVG e porcentagem de germinação para as sementes de maior tamanho. No entanto, segundo os mesmos autores, para grumixameira (Eugenia brasiliensis), não houve diferenças significativas nesses valores em relação ao tamanho da semente. Assim, confirma-se a importância do estudo da influência do tamanho de sementes sobre a germinação, em espécies frutíferas.

De acordo com Carvalho \& Nakagawa (1983), as sementes de maior tamanho, geralmente, foram mais bem nutridas durante o seu desenvolvimento, possuindo embriões bem formados e com maior quantidade de substâncias de reserva, sendo, conseqüentemente, as mais vigorosas. Popinigis (1977) afirmou que o tamanho da semente, em muitas espécies, é indicativo de sua qualidade fisiológica. Assim, dentro do mesmo lote, as sementes pequenas apresentam menor germinação e vigor do que as sementes de tamanho médio e grande.

Concluiu-se que os frutos, sementes e plântulas de Syzygium malaccense (jambo-vermelho) possuem características morfológicas bastante homogêneas e confiáveis para a identificação da espécie. As sementes de jambo-vermelho de menor tamanho possuem menor desempenho germinativo e vigor do que as de tamanho médio e maior.

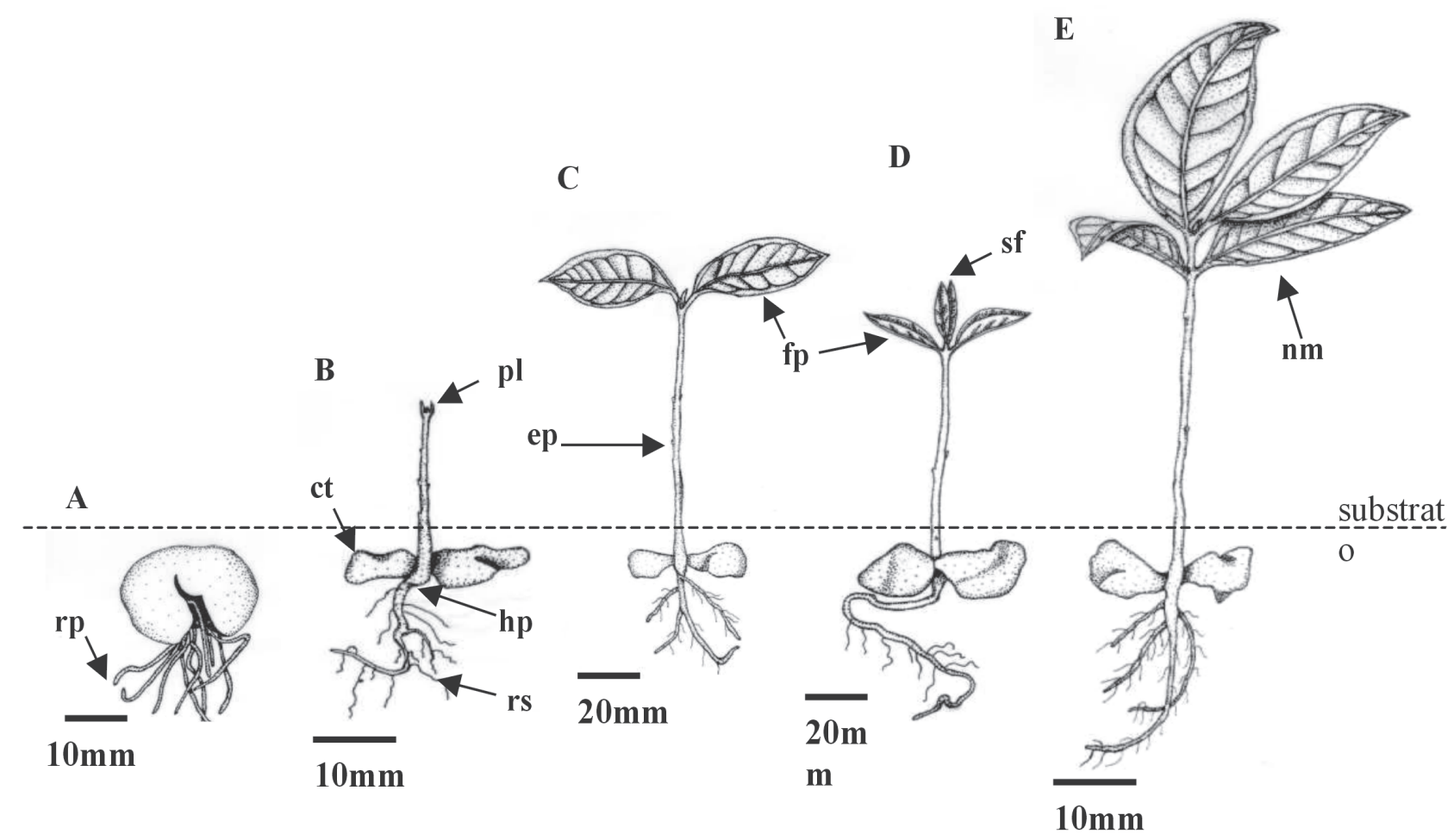

FIGURA 4 - Seqüência de germinação de sementes de jambo-vermelho: A) raiz primária (rp); B) plântula com raízes secundárias (rs) e plúmula (pl); hipocótilo (hp); epicótilo (ep); C) expansão da folha primária (fp) e início do desenvolvimento do segundo par de folhas (sf); E) segundo par de folhas em expansão; F) planta jovem, com nomófilos (nm). 


\section{REFERÊNCIAS}

AHMAD F. B.; ISMAIL G. Medicinal plants used by kadazandusun Communities around crocker range. ASEAN Review of Biodiversity and Environmental Conservation (ARBEC). Disponível em: $<\underline{\text { http:/ }}$ /www.arbec.com.my/pdf/art1janmar03.pdf $>$. Acesso em: 24 out. 2005.

BARROSO, G. M.; MORIM, M. P.; PEIXOTO, A. L.; ICHASO, C. L. F. Frutos e sementes: morfologia aplicada à sistemática de dicotiledôneas. Viçosa: UFV, 1999. 443 p.

BELTRATI, C.M. Morfologia e anatomia de sementes. Rio Claro: Departamento de Botânica,Instituto de Biociências, UNESP, 1992. 108p.

CARVALHO, N. M.; NAKAGAWA, J. Sementes: ciência, tecnologia e produção. Campinas: Fundação Cargill, 1983. 429p.

CAVALCANTE, P.B. Frutas comestíveis da Amazônia. 6.ed. Belém: CNPq/Museu Paraense Emílio Goeldi, 1996. 279p.

DAMIÃO FILHO, C. F. Morfologia e anatomia de sementes. Jaboticabal: FCAV/UNESP, 1993. 145p. Apostila.

DONADIO, C. D.; NACHTGAL, J.C.; SACRAMENTO, C. K. Frutas exóticas. Jaboticabal: FUNEP, 1998. 279p.

GARWOOD, N.C. Morphology and ecology of seedlings, fruits and seeds of selected Panamanian species. Botanische Jahrbuecher fuer Systematik, Stuttgart, v.117, p.1-152, 1995.

GUNN, C.R. Seed topography in the Fabaceae. Seed Science and Technology, Zurich, v. 9, n. 3, p. 737-757, 1981.

KUNIYOSHI, Y.S. Morfologia da semente e da germinação de 25 espécies arbóreas de uma floresta com araucária. 1983. 233f. Dissertação (Mestrado) - Universidade Federal do Paraná, Curitiba, 1983.

KUROSAWA, C. Jambo-Vermelho. Disponível em: <http:// redeg lobo.g lobo.com/c g i - bin/g loborural/ montar_texto_ult.pl?controle=2040>.Acesso em: 04 jun. 2004.
MAGUIRE, J. D. Speed of germination - aid in selection aid evolution for seedling emergence and vigor. Crop Science, Madison, v.2, n.2, p.176-177, 1962.

MIQUEL, S. Morphologie fonctionelle de plantules d'especes forestiéres du Gabon. Bulletin du Museum d'Histoire Naturelle de Paris, Paris, v.9, p.101-121, 1987.

OLIVEIRA, E. C. Morfologia de plântulas. In: AGUIAR, I. B.; PIÑARODRIGUES, F. M. C.; FIGLIOLIA, M. B. (Coord). Sementes florestais tropicais. Brasília: ABRATES, 1993. p.175-213.

OLIVEIRA, I.V.M.; ANDRADE, R.A.; MARTINS, A.B.G. Influência do tamanho da semente na precocidade de germinação de bacuripari (Rheedia gardneriana). In: REUNIÃO ANUAL DA SOCIEDADE INTERAMERICANADE HORTICULTURATROPICAL, 49., 2003. Fortaleza. Anais... p.88.

OLIVEIRA, I.V.M.; ANDRADE, R.A.; MARTINS, A.B.G. Influência do tamanho da semente na precocidade de germinação de grumixama (Eugenia brasiliensis). In: REUNIÃO ANUAL DA SOCIEDADE INTERAMERICANADE HORTICULTURA TROPICAL, 49., 2003, Fortaleza, CE. Anais... p.97.

OLIVEIRA, M.T.; BELTRATI, C.M. Morfologia e desenvolvimento das plântulas de Inga fagifolia e Inga uruguensis. Turrialba, San Jose, v.42, p.306-313, 1992.

POPINIGIS, F. Fisiologia da semente. Brasília: AGIPLAN, 1977. 289p.

SILVA, L. M. M.; MATOS, V. P.; PEREIRA, D. D.; LIMA, A. A. Morfologia de frutos, sementes e plântulas de Luetzelburgia auriculata Duke (pau-serrote) e Pterogyne nitens Tul. (madeira-nova-do-brejo) Leguminosae. Revista Brasileira de Sementes, Brasília, v.17, n.2, p.154-159, 1995.

VIDAL, V. N. Considerações sobre as sâmaras que têm ala paranuclear. Rodriguesia, Rio de Janeiro, v.30, n.47, p.109-168, 1978. 